\title{
The Mental Skills Training of University Soccer Players
}

\author{
Hassan Sadeghi \\ Department of Sports Studies, University Putra Malaysia \\ Tel: 60-3-8946-4276 E-mail: Hassan.Sadeghi81@yahoo.com \\ Mohd-Sofian, Omar-Fauzee \\ Sports Academy, University Putra Malaysia \\ Tel: 60-3-8946-4275 E-mail: dromarfauzee@yahoo.com \\ Marjohan Jamalis \\ Department of Sports Studies, University Putra Malaysia \\ Tel: 60-3-8946-4276 E-mail: zarimad@gmail.com
}

Rozita Ab-Latif

Faculty of Sport Science and Recreation, Universiti Teknologi MARA Malaysia

E-mail: 65.roland@gmail.com

Majid Chahrdah Cheric

Faculty of Education and Psychology, Department of Sports science, Shiraz University, Iran

E-mail: mcheric14@yahoo.com

\begin{abstract}
The purpose of this study is to identify the kind of mental skills training needed most by the university soccer players. Eight male university football players (aged 25 to 36) from one large university in Kuala Lumpur agreed to participate in this study. On average, they have 10 years of playing experience. All of them have signed the informed consent letter to be tape-recorded. The interview transcripts were then hierarchically content analyzed to identify the themes. The findings revealed four themes emerged which are imagery, goal setting, self-talk, and relaxation. These four themes were the most needed psychological skill training by the respondents. Recommendations for future studies were also suggested.
\end{abstract}

Keywords: Psychological skill training, Self-talk, Goal setting, Relaxation, Imagery, Soccer players

\section{Introduction:}

The psychological factors involved in athletic performance have long been of interest to athletes, coaches, sport psychologists and sports scientists. Empirical studies have largely focused on individual psychological factors and their influence on performance which includes confidence, motivation, attention, visualization, and psychosomatic skills (Gucciardi, Gordon, \& Dimmock, 2009). Similarly, some studies indicated that the use of mental skills such as goal setting, imagery, relaxation, and self-talk are important areas in the field of sport psychology (Vealey, 2007; Williams \& Harris, 2001). They also asserted that goal setting as attaining a specific standard of proficiency on a task, usually within a specified time limit can increase performance during competition. Moreover, imagery as using all the senses to re-create or create an experience in the mind helps athletes to perform better and increase self-confidence (Rattanakoses, et al., 2009).

Furthermore, relaxation acts as a technique to rid the muscles of disorder tension interfering with performance and help the rest of the body and mind. It also promotes confidence in the athletes' ability to lessen or decrease the effect of undesirable thoughts and feelings. In addition, self-talk has been defined as occurring verbalizations or statements about something as well as increase performance and skills in sport (Howland, 2006; Vealey, 2007). In consequence, mental training can improve performance of athletes in order to achieve championship in competition. 
Practitioners sometimes have difficulties building effective mental training programs for individual athletes and teams. In spite of that, they also believe that mental training such as goal setting, imagery, relaxation, and self-talk had helped them before, during and after competition and practice to improve performance, energy management, stress management, attention, self-confidence and motivation (Burton \& Raedeke, 2008). Many of the sport psychology researches (e.g., Burton \& Raedeke, 2008; Robazza, Pellizzari, \& Hanin, 2004; Vealey, 2007) over the last decades have investigated the cognitive and emotional factors associated with athletic achievements in an attempt to identify the personality characteristics of skilled athletes and the mental preparation strategies that they use to perform successfully.

There are evidences that an athlete needs to work with a mental training. For example, athletes who find it hard to maintain motivation during off-season training can use goal setting training to provide a sense of direction and purpose in their workouts. It is especially when he is unable to perform up to a desirable ability level in competition, using imagery effectively to focus on desired image and thus can develop attention skill. More successful athletes show a greater positive mental health profile by larger scores of energy and lower scores in such negative moods as tension, depression, anger, fatigue, and confusion, for example, using positive self-talk to raise self-confidence. On the other hand, researches have also found that negative self-talk can lower the athlete self-confidence level (Caruso, 2005). Research findings (i.e., Burton \& Raedeke, 2008; Caruso, 2005; Vealey, 2007; Williams, 2001) have shown that elite and successful athletes are more committed, motivated, self-confident, focused, and able to cope with adversity, and peak under pressure. Following the earlier approaches, researchers (Bertollo, Saltarelli, \&Robazza, 2009; Robazza \& Bortoli, 1998) have developed sport-specific questionnaires to test the mental skills of athletes across different competitive standards and sports. According to Bertollo et al. (2009), psychological variables and skills underlying peak performance have mainly been examined through qualitative interviews or both questionnaires and interviews. Practitioners can use this body of knowledge to plan, implement, and optimize psychological treatments, thereby helping experienced performers and beginners achieve their best.

\subsection{Individual Psychological factors and Performance}

Researchers (e.g., Burton \& Raedeke, 2008; Vealey, 2007; Williams, 2001) have focused on individual psychological factors (goal setting, relaxation, imagery, and self-talk) and their influences on performance. Recently, researchers have adopted a holistic approach in which the whole and the interdependence of its parts are emphasized (Gammage, Hardy, \& Hall, 2001; Gucciardi, et al., 2009; Vealey, 2007; Williams, 2001). They also believed that mental skills help athletes and coaches to increase performance during practice and competition and affect the athletes' success in their tournament or game. For example, goal setting improves playing skill, techniques, and strategies.

\subsubsection{Goal Setting}

Goal setting has received some attention and its use has been supported by personal trainers and popular fitness magazines (Williams, 2001). Locke, Shaw, Saari, and Gary (1981) indicated goals setting affect performance by directing attention, mobilizing effort, increasing persistence, and motivating strategy development. This fact was supported by Burton and Raedeke (2008). Goals are like magnet that attracts athletes to higher ground and new horizons. They give their eyes a focus, their mind an aim, and their strength a purpose. Moreover Bueno, Weinberg, Fernandez-Castro, and Capdevila (2008) also asserted that both motivational and emotional mechanisms were important mediators in improving the efficacy of goal setting in endurance sports. Meanwhile, sport psychologist researchers (Burton \& Raedeke, 2008; Vealey, 2007) believed that there is a close relationship between goal setting and imagery during practice and competition.

\subsubsection{Imagery}

Another mental skill that researchers in the exercise domain have recently started to examine is imagery. Trainers reported the frequent use of imagery and their use of imagery is related to their exercise behavior (Gammage, Hall, \& Rodgers, 2000Vealey \& Greenleaf, 2001;). Imaging a sport skill is similar to performing the skill, except that athletes experience the action only in their mind. Similarly, Omar-Fauzee, Daud, Abdullah, and Rashid (2009) also claim that imagery was used as the method in which people feels themselves through their minds. They can imagine themselves that ways have directed them to learn and improve skills. This imagery can make performance simple as it is out of individual's skills. As the research on exercise imagery is positive, more action is needed to better understand how imagery affects exercise behavior (Gammage, et al., 2000; Vealey, 2007). Studies showed the effect of mental imagery on the enhancement of athletic performance (Jones \& Stuth, 1997), learning of basketball tactical strategies (Guillot, Nadrowska, \& Collet, 2009), motor performance and skills (Papadelis, Kourtidou-Papadeli, Bamidis, \& Albani, 2007; Wei \& Luo, 2009). According to those 
literature reviews, imagery as an element of sport psychology skill or mental training tool can be useful on the success of athletes and prolong physical performance especially during competition.

\subsubsection{Relaxation}

Because the stressors which are usually present in sport often create physical tension, physical relaxation may be useful to help athletes manage their physical levels energy to allow them to perform well (Vealey, 2007). Likewise, Burton and Raedeke (2008) declared that relaxation is to decrease unwanted muscular tension, reduce extreme activation of the sympathetic nervous system, and calm the mind by keeping it productively occupied. Researchers agreed that successful elite athletes regularly use relaxation technique to manage their physical energy (Howland, 2006; Neiss, 1988;Williams \& Harris, 2001) Additionally, Newmark and Bogacki (2005) also described the use of relaxation techniques available to increase athletic performance. Coaches recognized the importance of relaxation in competitive winner, often encouraging athletes either to relax or to "psych up" if they want to be more successful. This fact was supported by Kulmatycki and Bukowska (2007) that affects relaxation techniques on the achievement of better results as well as an important reduction of anxiety and improvement of self-confidence.

\subsubsection{Self-talk}

One of the mental skills that researches have been conducted in the mental training domain is self-talk (Burton \& Raedeke, 2008; Vealey, 2007; Williams, 2001). Typically, self-talk has been defined as occurring anytime one thinks about something (Gammage, et al., 2001). On the other hand Self-talk is defined as "(a) verbalizations or statements addressed to the self; (b) multidimensional in nature; (c) having interpretive elements associated with the content of statements employed; (d) is somewhat dynamic; and (e) serving at least two functions, instructional and motivational, for the athlete', (Edwards, Tod, \& McGuigan, 2008). Researchers have found that self-talk enhances performance and skills in sport (e.g., Hardy, 2006; Hardy, Hall, \& Alexander, 2001). Influences on vertical jump male Rugby union players (Edwards, et al., 2008), Affects Female Youth Soccer Performance (Johnson, Hrycaiko, Johnson, \& Halas, 2004). Furthermore, Vealey (2007) suggested that creative self-talk is also effective for using strategy, psyching up emotion and effort, relaxation and calming down, attention focusing, maintaining self-confidence and self assessment. In this type of mental training, athletes make their feeling and perception clear, evaluate themselves, and give themselves instructions or reinforcement.

\subsection{Problem Statement}

Less-proficient athletes may be helped to learn, refine, and practice mental skills and strategies aimed at gaining personal control of weak states and improving psychophysical conditions that make performance easy. For this purpose, sport psychology consultants have developed and applied a remarkable number of mental training programs across a range of individual and team sports (Bertollo, et al., 2009). Likewise, football player's team is one of the sports that deal with psychological factor and mental training.

The soccer games are basically attractive to millions of people worldwide. Watching or playing had provided deep enjoyment for those attending or participating in play (Reilly, Clarys, \& Stibbe, 1993). Football players have a close relationship with psychological characteristics. Soccer, like other sports requires not only a high level of physical performance but also mental training and mental skills (Junge, et al., 2000). In addition, Barth and Zempel (2004) argued that factors of goal setting, imagery, relaxation, and self-talk have influence on football players' performance. They also claimed that sports are more than just muscles. They indicated that the impulses for the muscle come from the brain or every complicated movement that an athlete performs is actually controlled by the nerve connection within the brain. For example, mental toughness in Australian football is a collection of values, attitudes, behaviors, and emotions that enable players to persevere and overcome any obstacle, adversity, or pressure experienced. It also maintains concentration and motivation when things are going well to achieve goals continuously (Gucciardi, et al., 2009). Researchers and coaches do not know what kind of mental training can help the football players more to increase the performance during competition and practice (Barth \& Zampel, 2004; Junge, et al., 2000). Therefore, in order to overcome those problems, the purpose of this study is to help the coach identify the types of mental skills needed by athletes. In particular, this study will focus on college students in Malaysia and searching for the main psychological skill trainings assist coaches to set up the psychological training in the future.

\subsection{Purpose of study}

Although, researchers have found that mental skills have better impact on athlete's performance, not many studies in Malaysia focus in this area of research (Omar-Fauzee, See, Geok, \& Latiff, 2008). Therefore, in order 
to explore the mental skills among Malaysia athletes the purpose of this study is to investigate the type of mental skills that athletes needed most to overcome their mental skills problems before, during, and after every game.

\section{Methodology}

\subsection{Participant}

Eight student-athletes from one of the large universities in Kuala Lumpur have agreed to participate in the study. The players ranged from 25 to 36 years of age. On average, they had 10 years of football playing experience. Since this is a qualitative method to study, only those who are willing to participate and have signed an inform consent letter to be tape-recorded will be examined.

\subsection{Procedure}

The athletes were met at their training complexes and interviews were conducted in programmed field. The general scope of the study was explained to the athletes before starting the interview. Emphasis was placed on the potential benefits deriving from a thoughtful analysis of an individual's strategies, strengths, and weaknesses. Athletes were informed that their participation was voluntary and they were assured of the complete confidentiality and anonymity of their notes. All participants provided written consent and were then involved in organized and face-to-face individual interviews lasting 60-90 minutes. All interviews were tape recorded and conducted by the same individual who was trained in qualitative research methodology and knowledgeable about sport psychology.

\subsection{Data Analysis}

Analysis of the qualitative data in this study followed the procedure used by (Robazza \& Bortoli 1998) and then employed by (Bertollo, et al., 2009). The preparation and analysis of interview data were progressed as follows:

All eight tape-recorded interviews were transcribed exactly resulting in 60 single-spaced pages of interview data regarding the focus of the study.

Two investigators (the two authors) read and re-read all the transcripts until they were completely familiar with each participant. They also listened to each taped interview so they could interpret the meanings associated with tone of voice, pauses. The investigators also read the transcripts collected during practice in relation to behavior and explanation and confronted them with the taped transcripts where football performance routine was described.

Independently, the two authors identified raw data themes characterizing each footballer's responses, and developed idiographic profiles or summary abstracts of each footballer. After extensive discussion, consensus was obtained on a joint profile for each footballer, as well as on a list of subsection raw data themes characterizing each athlete's responses.

(4) Idiographic profiles of each participant and all raw data themes were thoroughly discussed until consensus was reached. Therefore, agreement, or triangular consensus, was obtained on all idiographic profiles and all raw data themes.

(5) These sectional raw data themes characterizing each athlete's responses were compiled for all footballers. This resulted in a listing of raw data themes within each subsection that characterized all footballers.

(6) An inductive analysis was conducted to identify common themes of greater common lists of the subsection themes. Second-level themes were tagged 'higher-order themes' while the highest level themes were made as 'general dimensions'.

(7) As additional confirmation of the inductive analysis, the raw data themes, higher order themes and general dimensions were tested by conducting a deductive analysis whereby the investigators went back to the original transcripts and verified that all themes and dimensions were represented.

\section{Results}

Data analysis resulted in four kind of psychological mental training tools emerged from the interviews. They are imagery; goal setting, self-talk, and relaxation in Tables 1,2,3 and 4 provided a schematic of the hierarchical representation of the results of the analytic procedure. One hundred sixteen (116) raw data themes were identified by the participants as mental factors and strategies deemed important for football players. In the following sections, actual quotes are included to provide a coherent level of description and to prolong the interpretations drawn from the data. Furthermore, actual quotes enable the reader to judge the researchers' interpretations and to obtain out possible alternative interpretations. 


\subsection{Imagery}

The 42 raw themes identified as imagery factors emerged into three higher-order themes that included competition period, individual factor, and psychological skill (Table 1). During the interview, participants talked about the importance of imagery in the competition period. For example, one participant said:

'Before competition and training to cut the edge of my performance and to improve my skills, usually I do that with watching soccer movies'.

Using imagery after competition or training was useful. For instance, one participant said:

"After the competition I will review those mental pictures that I wanted to achieve".

Similarly, another participant said,

"Using imagery after practice or competition can be practical to monitoring skills that performed".

Related to competition period participants believed that employing imagery during the practice or competition also is affective for reviewing the skills that are performed. In the individual factor domain, one player gave an example: "I will imagine about the game before the competition to improve my performance". In addition to description of individual factor, they considered imagery can be useful for controlling and managing of participant during competition and practice. For example one participant said:

"Imaging before and during the competition can help me to control myself and manage my skills".

Participants also noted the psychological skill that can be important when the imagery used. For example one participant said:

"I will imagine from one day before the game to build my self- confidence". On the other hand, participants believed: "When we used the imagery automatically our motivation increased."

\subsection{Goal setting}

The 31 raw themes identified as goal setting factors emerged into three higher-order themes that included competition period, championship, and psychological skill (Table 2). During the interview, participant considered the importance of goal setting in the championship and before the competition and practice. They believe attention to goal leads them to improve championship feeling. For example one participant said:

"I will use goal setting to see the direction of my goal and the way to achieve the goal"

Participants also described how they developed psychological skill when they used the goal setting. For example, one participant emphasized the increase of motivation when he used the goal setting,

"When I think the goal my motivation systematically increases".

Another participant explained the effect of goal setting on self-confidence. For example:

"I believe that have closely relationship between goal settings and increase the self-confidence".

Also they asserted that when they used the goal setting, the attention increased and all focus were on their goal that should be achieved.

Participants considered competition period for goal setting. They tried to use the goal setting before the competition or practice. Some of them also assumed using the goal setting during the competition helped them to hold the motivation and another psychological skill for achieving the goal

\subsection{Self-talk}

The 27 raw themes identified as self-talk factors emerged into three higher-order themes that included competition period, individual factor, and psychological skill (Table 3). Participants also talked about self-talk before competition. Also, several of them believed in using self-talk during competition. In the individual factor area, for example, one participant said:

"When I talk with myself, I can do the best performance."

As such, some of the participants explained the effect of self-talk on the distraction. For instance one participant described:

"I will use psychology such as self-talk to avoid or to decrease the distraction."

Psychological skill is also influenced by self-talk. Participants described the effect of self-talk on the motivation and self-confidence. For instance, one participant said: 
"Positive self-talk will increase self-confidence and motivation but negative self-talk decrease self-confidence and motivation.

\subsection{Relaxation}

The 15 raw themes identified as relaxation factors appeared into three higher-order themes that included competition period, individual factor, and stress management (Table 4). Participants also talked about relaxation before competition. Also, on one hand, several of them trusted to use relaxation during competition.

"I will make a relaxation to my mind and also to my physical. It will increase my confidence".

On the other hand, some of the participants indicated the effect of relaxation on the stress. For instance one participant said:

"With the relaxation I can manage the stress during the competition and after the competition also I use it"

Finally, one participant talked about the performance. For instance, one participant said:

"My performance increased when I use relaxation".

In conclusion, participants clearly explained the mental training tools that they used. Players gave details about the benefits of mental training before, during, and after competition in those quotations. They also identified the important mental training tools and when they are most usable.

\section{Discussion}

The purpose of the present study was to gather qualitative information on the most important mental skills factors that contribute to improving their performances. It helps coaches and athletes to better understand the important kind of psychological skill for college students' soccer players. It also shows them when to use the mental trainings. Therefore, only representative interview quotes were selected for the purpose of the study. Related higher-order themes were combined into four general dimensions: (A) imagery, (B) goal setting, (C) self -talk, (D) and relaxation. The interview transcripts were then hierarchically content analyzed to identify the themes. The findings revealed that imagery, goal setting, self-talk, and relaxation themes the most needed psychological mental skills by football players. Additionally, this study focused on the psychological mental training tools to indicate which one is more important and usable for athletes.

Results showed that most athletes during this interview strongly agreed with imagery (figure 1) and they discussed on this and believed imagery could be useful before and during competition. Thus, the results are in line with other studies which have emphasized the imagery could improve their performance (Omar-Fauzee, et al., 2009; Papadelis, et al., 2007). The results of this study also emphasized some athletes believed that imagery can increase self-confidence and motivation. Guillot et al., (2009), found that imagery after practice or competition can be useful for recalling and monitoring the past skill. Based on the result of imagery, some athletes explained the effectiveness of imagery after competition or practice. Participants jumped into this conclusion that imagery after competition could help athletes to analyze the past performance.

Moreover, results showed that athletes had involved in the goal setting. On the other hand, they believed using goal setting before competition could affect on increasing motivation, attention, self-confidence, and focusing on championship (Figure 2). The above-mentioned report is supported by (Bueno, et al., 2008). On the other hand, (Burton \& Raedeke, 2008; Vealey, 2007) argued that goal setting not only increase playing skill, techniques, performance, but also increase focus and concentration that can be necessary for winning the competition.

Also, participants described other mental skills to be used in the mental training domain which is self-talk. The results of figure 3 showed that players emphasize self talk in order to achieve a higher level of training. They also mentioned that using self-talk during the competition can be useful. The results of this study reported that self-talk impact performance, motivation, and self-confidence. On the other side of the picture, some researchers (Edwards, et al., 2008; Johnson, et al., 2004) found the same result and supported the results of this study by applying questionnaire. But, this study was investigated via interview and questionnaire.

Finally participants talked about relaxation among football players (figure 4). Relaxation helps athletes manage their physical energy levels for performing well. In this interview, a few football players believed the benefits of relaxation is after training and competition. This finding is completely supported by researchers (Vealey, 2007; Williams, 2001). The results of this study also emphasis the effects of relaxation on decreasing stress and increasing energy. These results are consistent with previous studies (Burton \& Raedeke, 2008; Newmark \& Bogacki, 2005). Participants also confirm that relaxation helps athlete to achieve the best performance. As a suggestion, it is ideal when coaches prepare the multiple kinds of mental training for their athletes to give the 
best performance and achieve the championship. Ample attention should be paid to the psychological mental training tools such as imagery, goal setting, self-talk, and relaxation should be paid attention to.

\section{Conclusion}

The results of interviews showed an insightful knowledge on psychological factor and mental training approaches that are associated with effective football performance. The psychological factors involved in athletic performance have long been of interest to athletes, coaches, and sport psychologists. Mental skills such as goal setting, imagery, relaxation, and self-talk are important areas in the field of sport psychology. The soccer players, like players of other sports involve in mental training, believed that choosing more efficient kind of mental training will be an important factor to make football players successful (Junge, et al., 2000; Thelwell, Greenlees, \& Weston, 2006).

Overall findings indicated all mental trainings such as goal setting, imagery, relaxation, and self-talk are important during competition and have positive effects on competition result. This study was an attempt to identify the use of mental training for football players. This study showed that the imagery and goal setting are deemed important and useful for football players before, during, and after competition and practice. Thus, the results of this study of imagery are consonant with the finding of study of imagery of athletes focusing on the athletes' performance conducted by (Gammage, et al., 2000; Omar-Fauzee, et al., 2009). Also, the finding of the study of goal setting is consonant with the results of study about goal setting focusing on athletes' performance conducted by (Bueno, et al., 2008; Locke, et al., 1981). But, with a close look, these results of study showed the importance of imagery for football players and addressed more at that kind of mental training in their athletic life. However, the results suggested that imagery training might improve the motivation, energy management, attention, stress management, and self-confidence (Burton \& Raedeke, 2008).

In conclusion, sport psychology consultants should examine the performers' mental skill training and sources of concern very carefully. They are very important because they are often the result of long periods of training, repeated competitive experiences of success and failure. They also are important as educational influences of significant persons, such as coaches, teachers, and parents. In an attempt to prepare systematic programs to develop mental skill, sport psychologists should pay attention to the individual differences as well as the specific physical, technical, and psychological necessities of a sport. A basic knowledge of the characteristics of a certain sport and a deep understanding of the athletes' thoughts and behaviors pre, during, and after competition are necessary to help performers achieve their personal in the best way.

\section{References}

Barth, K. \& Zempel, U. (2004). Training soccer. Oxford: Meyer and Meyer Sport.

Bertollo, M., Saltarelli, B. \& Robazza, C. (2009). Mental preparation strategies of elite modern pentathletes. Psychology of Sport and Exercise, 10(2), 244-254.

Bueno, J., Weinberg, R. S., Fernandez-Castro, J. \& Capdevila, L. (2008). Emotional and motivational mechanisms mediating the influence of goal setting on endurance athletes' performance. Psychology of Sport an Exercise, 9(6), 786-799.

Burton, D., \& Raedeke, T. (2008). Sport psychology for coaches. Champaign, IL: Human Kinetics.

Caruso, A. (2005). Sports Psychology Basics. Cardinal Publishers Group.

Edwards, C., Tod, D. \& McGuigan, M. (2008). Self-talk influences vertical jump performance and kinematics in male rugby union players. Journal of Sports Sciences, 9(1), 1-7.

Gammage, K., Hall, C. \& Rodgers, W. (2000). More about exercise imagery. Sport Psychologist, 14(4), 348-359.

Gammage, K., Hardy, J. \& Hall, C. (2001). A description of self-talk in exercise. Psychology of Sport and Exercise, 2(4), 233-247.

Gucciardi, D. F., Gordon, S. \& Dimmock, J. A. (2009). Development and preliminary validation of a mental toughness inventory for Australian football. Psychology of Sport and Exercise, 10(1), 201-209.

Guillot, A., Nadrowska, E. \& Collet, C. (2009). Using Motor Imagery to Learn Tactical Movements in Basketball. Journal of Sport Behavior, 32(2), 189.

Hardy, J. (2006). Speaking clearly: A critical review of the self-talk literature. Psychology of Sport and Exercise, $7(1), 81-97$. 
Hardy, J., Hall, C. \& Alexander, M. (2001). Exploring self-talk and affective states in sport. Journal of Sports Sciences, 19(7), 469-475.

Howland, J. M. (2006). Mental Skills Training for Coaches to Help Athletes Focus Their Attention, Manage Arousal, and Improve Performance in Sport. Journal of Education, 187(1), 49-66.

Johnson, J., Hrycaiko, D., Johnson, G. \& Halas, J. (2004). Self-talk and female youth soccer performance. Sport Psychologist, 18(1), 44-59.

Jones, L. \& Stuth, G. (1997). The uses of mental imagery in athletics: An overview. Applied and Preventive Psychology, 6(2), 101-115.

Junge, A., Dvorak, J., Rosch, D., Graf-Baumann, T., Chomiak, J. \& Peterson, L. (2000). Psychological and sport-specific characteristics of football players. The American Journal of Sports Medicine, 28(suppl_5).

Kulmatycki, L. A. \& Bukowska, K. (2007). Differences in experiencing relaxation by sport coaches in relation to sport type and gender. Human Movement, 8(2), 98-103.

Locke, E. A., Shaw, K.N., Saari, L.M. \& Gary, L.P., (1981). Goal Setting and Task Performance: 1969-1980. American Psychological Association, 90(1), 125-152.

Neiss, R. (1988). Reconceptualizing relaxation treatments: Psychobiological states in sports. Clinical Psychology Review, 8(2), 139-159.

Newmark, T. S. \& Bogacki, D. F. (2005). The Use of Relaxation, Hypnosis, and Imagery in Sport Psychiatry. Clinics in Sports Medicine, 24(4), 973-977.

Omar-Fauzee, M., Daud, W., Abdullah, R. \& Rashid, S. (2009). The Effectiveness of Imagery and Coping Strategies in Sport Performance. European Journal of Social Sciences, 9(1), 97-108.

Omar-Fauzee, M. S., See, L. H., Geok, S. K. \& Latiff, R. A. (2008). The relationship between the task and ego orientations and coping strategies among universities athletes. The ICHPER.SD Journal of Research, 3, 107-111

Papadelis, C., Kourtidou-Papadeli, C., Bamidis, P. \& Albani, M. (2007). Effects of imagery training on cognitive performance and use of physiological measures as an assessment tool of mental effort. Brain and Cognition, 64(1), 74-85.

Rattanakoses, R., Omar-Fauzee, M.S., Geok, S.K., Abdullah, M. C., Choosakul, C., Nazaruddin, M.N. \& Nordin, H. (2009). Evaluating the relationship of imagery and self-confidence in female and male athletes. European Journal of Social Sciences, 10, 129-142.

Reilly, T., Clarys, J. \& Stibbe, A (1993). Science and Football II. London: E and FN Spone.

Robazza, C. \& Bortoli, L. (1998). Mental preparation strategies of Olympic archers during competition: An exploratory investigation. High Ability Studies, 9(2), 219-235. 25

Robazza, C., Pellizzari, M. \& Hanin, Y. (2004). Emotion self-regulation and athletic performance: An application of the IZOF model. Psychology of Sport and Exercise, 5(4), 379-404.

Thelwell, R., Greenlees, I. \& Weston, N. (2006). Using Psychological Skills Training to Develop Soccer Performance. Journal of Applied Sport Psychology, 18(3), 254-270.

Vealey, S. R. (2007). Mental Skills Training in Sport. In G. Tenenbaum, R. Eklund and R. Singer (Eds.), Handbook of sport psychology. New Jersey: Wiley.

Vealey, S. R. \& Greenleaf, C. A. (2001). Seeing is believing: Understanding and using imagery in sport. In J. M. Williams (Ed.), Applied sport psychology: Personal growth to peak performance. California: Mayfield.

Wei, G. \& Luo, J. (2009). Sport expert's motor imagery: Functional imaging of professional motor skills and simple motor skills. Brain Research, In Press, Corrected Proof.

Williams, J. M. (2001). Applied sport psychology: Personal growth to peak performance. Mayfield.

Williams, J. M. \& Harris, V. D. (2001). Relaxation and energization technique for regulation of arousal. In J. M. Williams (Ed.), Applied sport psychology: Personal growth to peak performance. California: Mayfield. 
Table 1. Inductive analysis of Imagery

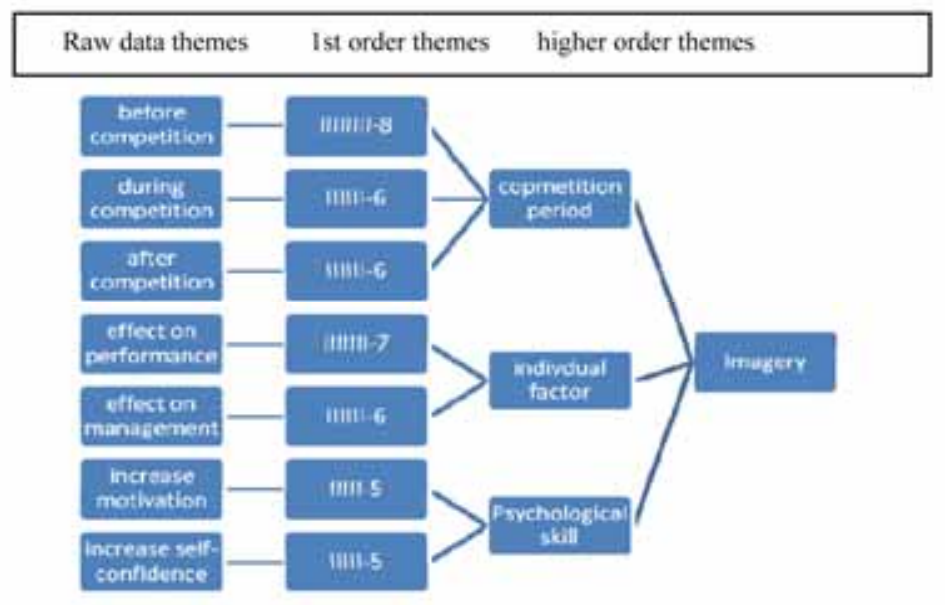

Table 2.Inductive analysis of Goal setting

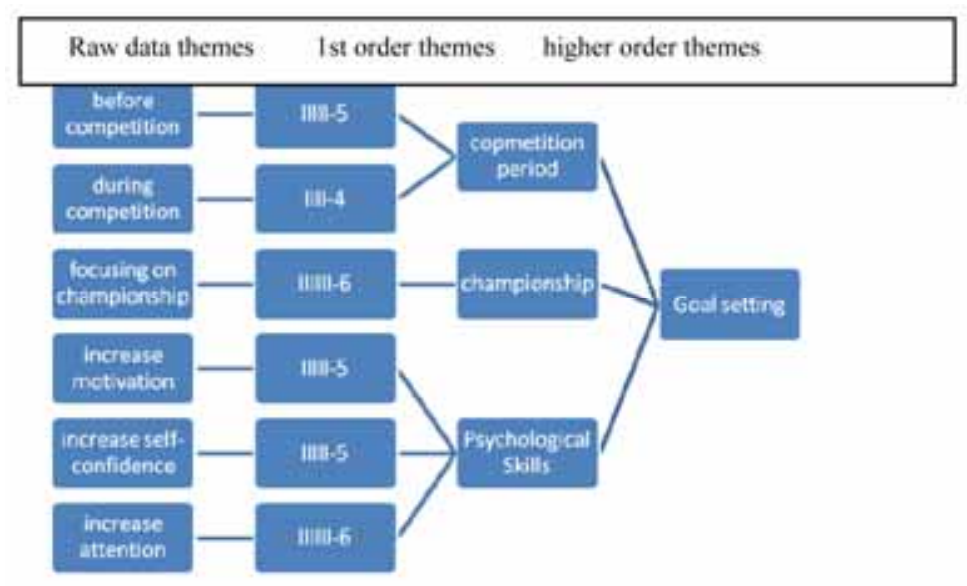

Table 3. Inductive analysis of self-talk

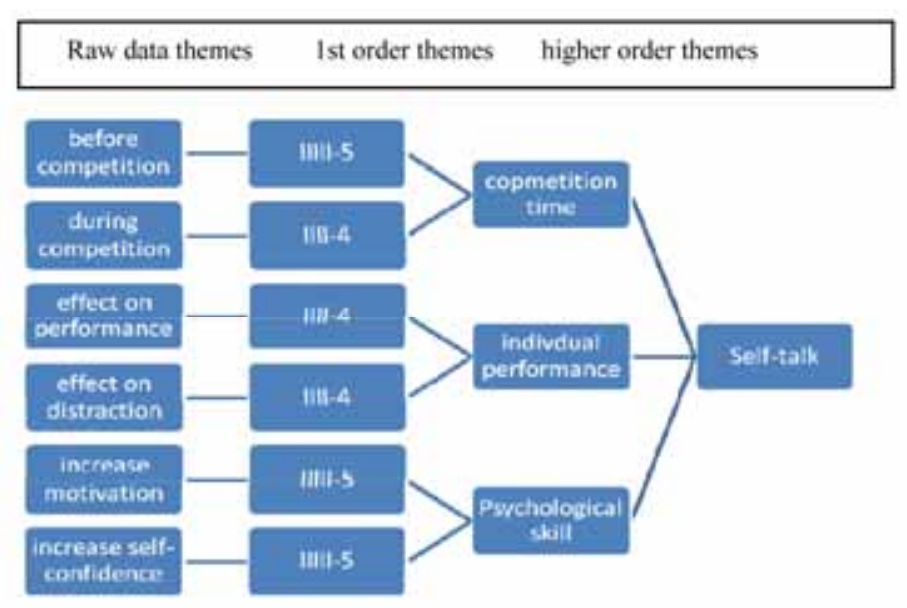


Table 4. Inductive analysis of Relaxation

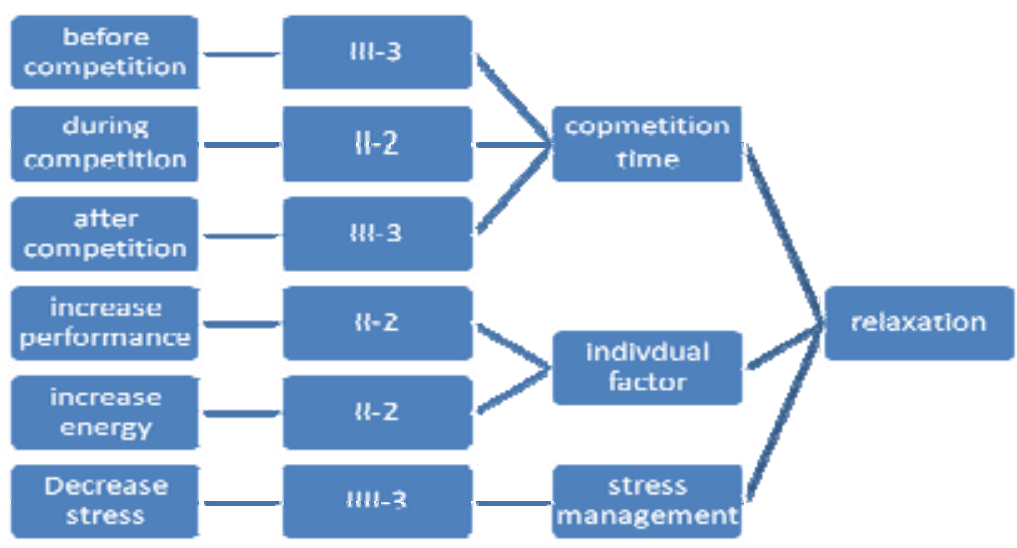

